\title{
Perception of Nigerian physiotherapists on enlistment, legislation and benefits of supplementary prescribing
}

\author{
Onigbinde Ayodele Teslim*, Tijani Aishat Idowu \\ Department of Medical Rehabilitation, College of Health Sciences, Obafemi Awolowo University, Ile-Ife, Osun State, Nigeria
}

Email address:

ayotesonigbinde@yahoo.co.uk (A. T. Onigbinde)

\section{To cite this article:}

Onigbinde Ayodele Teslim, Tijani Aishat Idowu. Perception of Nigerian Physiotherapists on Enlistment, Legislation and Benefits of Supplementary Prescribing. American Journal of Health Research. Special Issue: Supplementary Prescribing in Nigeria: A Needy Concept to Promote Clinical Physiotherapy Practice. Vol. 2, No. 5-1, 2014, pp.1-5. doi: 10.11648/j.ajhr.s.2014020501.11

\begin{abstract}
Supplementary prescribing is a modern clinical practice of utilizing allied health professionals to make drug administration easier and more accessible for patients. In the UK, physiotherapists have advanced from being supplementary to independent prescribers. Nigerian physiotherapists are still restricted to the traditional roles of clinical practice. This study aimed at determining the perception of Nigerian physiotherapists on being enlisted and legislated as supplementary prescribers. A self-administered questionnaire was administered to 313 licensed physiotherapists from 35 selected health institutions in Nigeria. The data were analyzed using descriptive statistics and non parametric inferential statistics (chi square). Results showed that a significant number of respondents $(85.3 \%)$ would like to be supplementary prescribers $\left(\mathrm{X}^{2}=407.08, \mathrm{P}<0.001\right)$ and would also want a legislation that would protect them against litigations. They would also like to prescribe analgesics (84.3\%), Non-steroidal anti-inflammatory drugs $(79.2 \%)$ and muscle relaxants $(78.9 \%)$. Very few (5.8\%) would like to prescribe all classes of drugs. Almost all respondents (90.4\%) desired to improve their pharmacotherapy knowledge in order to meet requirements that would be needed for supplementary prescribing. The perceived benefits included effectiveness of combined therapy $(83.4 \%)$ and timely drug intervention $(61.0 \%)$. In conclusion, most physiotherapists would like to be supplementary prescribers, and would like to prescribe analgesics, muscle relaxants and Non-steroidal anti-inflammatory drugs. They were also willing to gain more pharmacology knowledge.
\end{abstract}

Keywords: Perception, Nigerian Physiotherapists, Enlistment, Legislation, Supplementary Prescribing

\section{Introduction}

Physiotherapists have been supplementary and independent prescribers since 2005 and 2013 respectively at United Kingdom (UK). The British physiotherapists and podiatrists were the first allied health professionals in the world would be legislated to prescribe medicines for patients. Subsequently; the Medicines Act of 1968 in the UK was reviewed to develop a framework that reflects statuses of the new prescribers (Daily mail, 2012). They were legislated to prescribe medicines for chronic pains and respiratory diseases like asthma [1].

Supplementary prescribing reflects clinical multidisciplinary management of chronic conditions and it a voluntary partnership with an independent prescriber (doctor) to implement an agreed patient-specific clinical management plan (CMP) and to which the patient must consent to $[2,3,4]$. The supplementary prescriber is expected to have adequate experience and competency to manage the patient's specific condition as designed by the team [3]. Timely administration of medicine had been observed to maximize effective and timely use of resources [5].

Supplementary prescription has been a welcomed concept with positive developments since 2005, and this has made patients to experience less painful episodes, receive prompt attention and treatment, have increase in movements and functions, enhanced recovery and cost-effective treatment [6]. Supplementary prescribing (SP) has reduced doctor's workload and had also given them opportunity to concentrate on patients with acute conditions and the critically ill. Similarly, doctors have been able to focus on surgery and more complicated conditions that require more complex treatments.

Prescription requires and extensive knowledge of pharmacotherapy (oral and topical drugs). Nigerian physiotherapists face difficult challenges on knowledge because two recent studies revealed that they lack adequate knowledge of drugs $[7,8]$. In the UK, physiotherapists who 
are prescribers had additional education classes that involved at least 26 days in the classroom, and 12 days in practice with designated medical practitioners [4,9].

Globally, health professionals have the quest to increase their knowledge and scope of practice with the ultimate goals of providing quality care and reducing costs for clients. The pace of improving clinical physiotherapy education and practice in Africa appears to be slow and less dynamic [8]. In a recent study, most Nigerian physiotherapists wished to be supplementary prescribers [8]. However the limitations of the study were inadequate sample size and poor sampling techniques, thereby, limiting the generalization of the findings. The primary aim of this study was to investigate the opinion of physiotherapists on adding supplementary prescribing to their statutory roles.

\section{Methods}

\subsection{Study Settings}

The respondents were selected from government hospitals, private hospitals and clinics; and academic institutions in Nigeria.

\subsection{Sample and Sampling Techniques}

Multi-stage sampling technique was used to select the hospitals. Nigeria was first divided into three regions (North, South and West) and the 3 biggest University Teaching Hospitals, 1 national Orthopeadic hospital and 1 academic institution were selected from each region (totaling 15 settings). At the second stage, 15 other hospitals or clinics were identified and shortlisted in each region to make a total of 45 settings. The 45 settings were coded on papers into a ballot bowl and thoroughly mixed. Two independent physiotherapists were asked to pick 10 ballot papers each. The 20 ballot papers were de-coded and the hospitals/clinics were added to the initial 15 settings to make a total of 35 health institutions. Sample of convenience was used to select 313 respondents from the 35 health institutions. The major inclusive criterion was that respondents must have current practicing license.

\subsection{Research Design}

This study was a cross sectional exploratory survey study.

\subsection{Instrument}

A self administered questionnaire used by Onigbinde et al was slightly modified. Section B was modified by adding 5 relevant options on likely benefits or reasons for supporting SP in order to fulfill the aims and objectives of the study [8]. The new inclusions are:

a. SP will reduce workload on doctors

b. Physiotherapists will be relevant in chronic conditions

c. Relevant in acute conditions

d. SP will make medical management more accessible to patient e. Doctors will concentrate more patients with critical illness and those who require surgery

The questions were kept simple in a Yes or No format.

\subsection{Procedure}

Ethical approval was granted by the Health Research Ethics Committee (HREC), Institute of Public Health (IPH/OAU/12/132), Obafemi Awolowo University, Ile-Ife, Osun State, Nigeria. The heads of study settings also granted permission for conduction of the study. In order to maintain anonymity; participants' names were not required in the questionnaire. The questionnaire was administered to respondents in their offices and copies of the questionnaire were completed by respondents in the presence of at least one of the investigators. They all completed the questionnaire without time limit.

\subsection{Data Analysis}

The data were analyzed using descriptive statistics of frequency, mean, percentages and standard deviation. There were multiple choice options in some sections; hence, analyses were based on valid percentages for each option. Also, Non- parametric inferential statistics (Chi-Square) was used to compare number respondents who differ in choice of options. Statistical Package for Social Sciences Software (SPSS Inc., Chicago, IL, USA) was used to analyze the data.

\section{Results}

\subsection{Demographics and Academic Information}

The mean age of respondents was $32.90+8.26$ years and mean year of clinical experience was $8.54+7.60$ years. There are 133 male $(42.5 \%)$ and 178 female $(56.9 \%)$ were female. Two respondents $(0.6 \%)$ did not indicate their sex and educational qualifications. Other demographic details are in table 1 .

\subsection{Awareness and Opinion on Supplementary Prescribing}

Table 1. Gender, Qualifications and Work settings of respondents

\begin{tabular}{lll}
\hline Variables & Frequency & Percentage \\
\hline Gender: Male & 133 & 42.5 \\
Female & 178 & 56.9 \\
Nil response & 2 & 0.6 \\
Qualifications: Bachelor & 234 & 74.8 \\
Master & 63 & 20.1 \\
Doctorate & 14 & 4.5 \\
Nil & 2 & 0.6 \\
Work settings: Private & 22 & 7.0 \\
State & 63 & 20.1 \\
Teaching & 153 & 48.9 \\
Academics & 10 & 3.2 \\
Others & 60 & 19.2 \\
Nil & 5 & 1.6 \\
\hline
\end{tabular}

A significant number of respondents [248, (79.2\%)] were aware that Physiotherapists are supplementary prescribers in the UK $\left(\mathrm{X}^{2}=117.97, \mathrm{P}<0.001\right)$. Similarly, a significant 
number supported enlistment and change in status to that of supplementary prescribers so as to be able to prescribe relevant oral and inject- table drugs (Table 2).

\subsection{Classes of Drugs, Knowledge and Interest in Pharmaco-Physiotherapy}

Two hundred and sixty four (84.3\%), 247, (78.9\%) and $248(79.2 \%)$ respondents would like to prescribe analgesics, muscle relaxants and Non - Steroidal Anti- inflammatory Drugs respectively. Distribution of other drugs is represented in figure 1.One hundred and thirty three respondents $(42.5 \%)$ agreed that their present knowledge on pharmacology was enough to prescribe oral and inject-table drugs (four respondents [1.3\%] did not respond to this question). A significant number of respondents disagreed that they have adequate knowledge of pharmacology to prescribe oral and inject- table drugs $\left(\mathrm{X}^{2}=5.98, \mathrm{P}=0.01\right)$. Similarly, a significant number (280) showed interest in gaining more knowledge in pharmacology $\left(\mathrm{X}^{2}=213.75, \mathrm{P}<0.001\right)$ while a significant number of respondents also supported a legislation that will officially permit physiotherapists to prescribe drugs $\left(\mathrm{X}^{2}=179.17, \mathrm{P}<0.001\right)$, (figure 2 ).

On sources of gaining more pharmacology knowledge, 261 respondents $(83.4 \%)$ opined that reviewing school curricular to encompass adequate pharmacology education would improve knowledge while 235 respondents $(75.1 \%)$ opined that continuing professional development programs would be a good source to improve physiotherapists' knowledge of pharmacology (Table 3).

Table 2. Change in Prescription Status of Physiotherapists

\begin{tabular}{lllll}
\hline Variables & Frequency $^{*}$ & $\mathbf{\%}$ & $\mathbf{X}^{\mathbf{2}}$ & $\mathbf{P}$ \\
\hline Awareness: Yes & 248 & 79.2 & & \\
No & 58 & 18.5 & 117.97 & $<0.001$ \\
Enlistment: Yes & 259 & 82.7 & & \\
No & 43 & 13.7 & 154.49 & $<0.001$ \\
Change: Yes & 267 & 85.3 & & \\
No & 39 & 12.4 & 407.08 & $<0.001$ \\
\hline
\end{tabular}

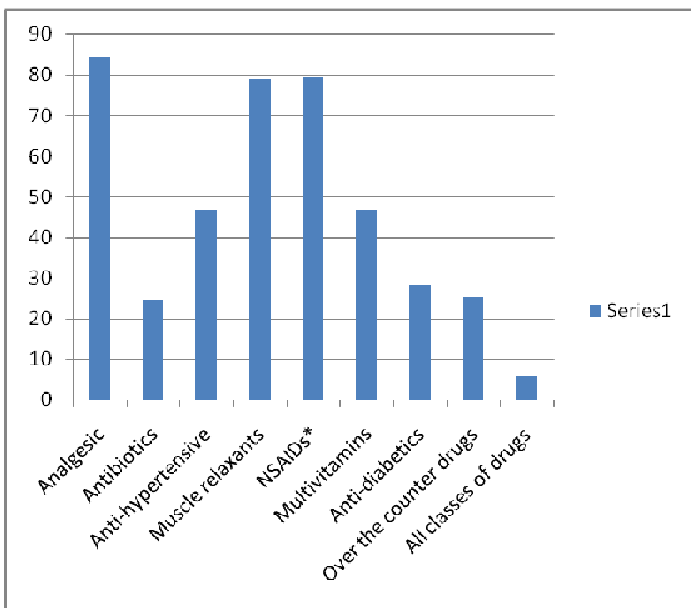

*Non-Steroidal Anti- Inflammatory Drugs

Figure 1. Frequency distribution of respondents on classes of drug prescriptions

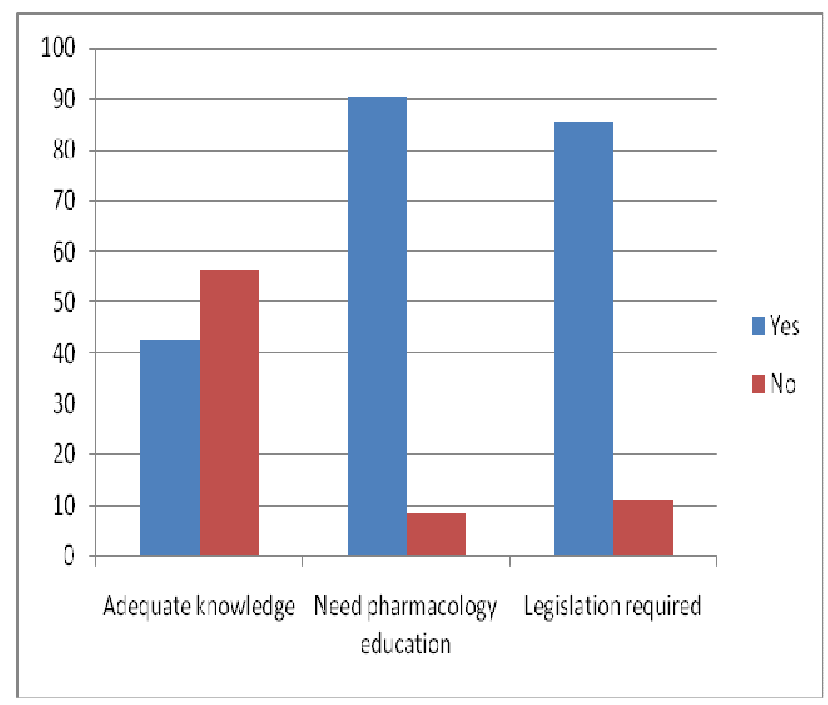

Figure 2. Legislation, knowledge and interest in pharmacology education

\subsection{Benefits of Legislating Drug Prescription}

Forty respondents $(12.8 \%)$ opined that it would reduce workload on doctors, 261 respondents $(83.4 \%)$ opined that patients would benefit more when physiotherapist provides both drug intervention and physiotherapy. One hundred and ninety one respondents $(61.0 \%)$ opined that it would provide opportunity for timely drug interventions while 60 respondents $(19.2 \%)$ opined that doctors would concentrate more on patients with critical illness and those requiring surgery (Table 4). Few respondents disagreed with legislating Physiotherapists to be supplementary prescribers (Table 5).

Table 3. Sources of improving pharmacology Knowledge

\begin{tabular}{lll}
\hline Sources & Frequency & Percentage (\%) \\
\hline Current schools training curricular & 154 & 49.2 \\
Reviewing school curricular & 261 & 83.4 \\
Doctor of Physiotherapy (DPT*) & 220 & 70.3 \\
Seminars and workshops & 213 & 68.1 \\
Transitional Doctor of & 152 & 48.6 \\
Physiotherapy Curriculum & & \\
Continuing Professional & 235 & 75.1 \\
Development Programmes & & \\
\hline
\end{tabular}

*commencing a 6 year academic programme

Table 4. Benefits of Drug Prescription by Physiotherapists

\begin{tabular}{lll}
\hline Variables & Frequency & Percentage (\%) \\
\hline Reduction of workload on Doctors & 40 & 12.8 \\
Effectiveness of combined therapy & 261 & 83.4 \\
Cost effective for patients & 133 & 42.5 \\
Inadequate physiotherapy & 74 & 23.6 \\
Effectiveness of Drugs & 15 & 4.8 \\
Reduction of Patient's waiting time & 151 & 48.2 \\
Increased confidence in physiotherapy & 178 & 56.9 \\
Relevancy in chronic conditions & 173 & 55.3 \\
Relevancy in acute conditions & 175 & 55.9 \\
Timely drug intervention & 191 & 61.0 \\
Doctors to concentrate on patients with & 60 & 19.2 \\
critical illness & & \\
\hline
\end{tabular}


Table 5. Reasons for objecting to $S P$

\begin{tabular}{lll}
\hline Variables & Frequency & Percentage (\%) \\
\hline Physiotherapy alone is effective & 12 & 3.8 \\
$\begin{array}{l}\text { Physiotherapy will lose her } \\
\text { traditional roles }\end{array}$ & 27 & 8.6 \\
$\begin{array}{l}\text { Drugs prescription is not in } \\
\text { curriculum }\end{array}$ & 26 & 8.3 \\
Increased workload & 9 & 2.9 \\
Duty of Doctors alone & 3 & 1.0 \\
Practicing physiotherapy by Doctors & 7 & 2.2 \\
\hline
\end{tabular}

\section{Discussion}

The demands to enhance drug accessibility to or for patients resulted to legislation which conferred privileges on professionals other than doctors to become prescribers [10]. It had been established that extensive knowledge of pharmacotherapy is relevant and useful to clinical physiotherapy practice. Onigbinde et al. reported that older physiotherapists did not have pharmacology training but they had acquired little knowledge during clinical practice [8]. However, in this study both physiotherapists with and without pharmacology education during undergraduate training opined that pharmacology has positive impacts in clinical practice. They also opined that adequate knowledge of pharmacology would have further increased the quality of practice [8].

In the UK, Physiotherapists have been able to prescribe medicines in accordance with a clinical management plan agreed with a doctor [8]. They have been prescriber for more than 9 years while respondents in our study have also been practicing for almost the same number of years; the lengthy year of practice might be the reason why majority of Nigerian physiotherapists were aware of the trend in the UK. It also showed that they were conversant with activities in the UK.

The desire of Nigerian physiotherapists to become supplementary prescribers and also demand for legislation were consistent with previous findings by Onigbinde et al [8]. There should be statutory guidelines and standard of care for physiotherapists such as there are guidelines for physicians, which they use for malpractice defense in case of litigations or suits. Failure to follow guidelines will be regarded as malpractice [8]. Onigbinde et al reported that most physiotherapists desired a change in their prescription status to professionals who will prescribe relevant oral and injectable drugs [8]. However, this clamour may meet stiffer opposition from Nigerian physicians as also reported by Onigbinde et al [8]. In a recent study, Nigerian doctors opposed granting physiotherapists the rights to drug prescription in Nigeria [12]. Similar trend had been reported in Australia where physicians rejected the growing trend of granting prescribing rights to non-medical health professionals, with the exception of dentists [13].

Amongst all classes of drugs, NSAIDs are the most common pharmaceutics used as adjunct therapy in the physiotherapy management of musculoskeletal conditions $[14,15]$. We observed that most physiotherapists preferred to prescribe analgesic, muscle relaxants and non- steroidal antiinflammatory drugs while few would like to prescribe antihypertensive and multivitamins. The interest in prescribing analgesic and muscle relaxants might be due to high frequency of cases of musculoskeletal dysfunctions and upper motor neuron lesions with symptoms of pain and spasticity respectively which physiotherapists commonly managed $[8,16]$. It should be appreciated that very few physiotherapists wanted to prescribe all classes of drugs. We felt these few respondents believed in specialization, it was likely that they thought of focusing on drug prescriptions for more relevant areas in physiotherapy.

It was evident that Nigerian physiotherapists doubted if they had enough pharmacology knowledge to be supplementary prescribers as majority admitted that they did not have good knowledge. The inadequate knowledge may be attributed to inadequate teaching during undergraduate training or lack of opportunity to practice what they learnt for fear of litigation as they were not licensed to prescribe drugs. Insufficient education and limited clinical practices may contribute to ineffective treatment of patients [17]]. However, a significant proportion was willing to improve their knowledge in order to meet the demand associated with supplementary prescribing. It is noteworthy, that physiotherapists in the UK who are prescribers were trained ahead of assuming the responsibilities. Most respondents identified review of school curricular, continuous professional development, commencing Doctor of Physiotherapy (DPT) programs and attending seminars and workshops as the most relevant sources to gain adequate knowledge of pharmacology.

Litigation is a major hindrance to prescribing without approval and most respondents wished that there should be legislation to permit them to officially be recognized as supplementary prescribers. There are benefits in SP, physiotherapeutic care of patient can be facilitated by the timely administration of medicine and this can only be achieved when rights to prescribe drugs were granted to physiotherapists. It is the only means of maximizing effective and timely use of resources [5]. Most respondents believed that changing the prescription status of physiotherapists from non-prescriber to supplementary prescribers would make patients to benefit more from the combination of medications and physiotherapy while some opined that it would increase patients' confidence in physiotherapists. Physiotherapists believe the opportunity to prescribe pain relief and other medicines will also help many patients respond more quickly to their physiotherapy, leading to faster improvements in movement, performance and function [6].

The benefits identified by respondents in this study are the successes that have been achieved in the UK $[18,19]$. They opined that supplementary prescribing would likely make medical management more accessible to patients, would reduce patients' waiting time, give opportunity of timely drug interventions and would be cost-effective. Some of the respondents opined that supplementary prescribing would likely be relevant at both acute and chronic conditions. 
However, SP had been noted to be mostly restricted to be most viable for the multi-disciplinary management of longterm conditions (chronic), [3]. Although, there are no legal restrictions as to the clinical conditions that may be managed by a supplementary prescriber but the best practice is that a supplementary prescriber should agree not to prescribe any medicine outside his/her area of competency [2].

We concluded that majority of physiotherapists wanted to be supplementary prescribers and would like to prescribe analgesics, muscle relaxants and Non-steroidal antiinflammatory drugs. They also desired that there should be legislation to protect them against litigations and they were willing to improve their pharmacology knowledge in order to meet challenges associated with supplementary prescribing. We recommend that the undergraduate curriculum in training institutions should be reviewed to integrate adequate pharmacology and organization of continuing professional development training. Also, the regulatory agencies of health should consider training of allied health professionals in drug prescription to meet the challenges of modern day health care services.

\section{References}

[1] Daily Mail (2012). British physiotherapists become first in the world to be allowed to prescribe medicines for their patients. Available at: <http://www.dailymail.co.uk/health/article2178025/British-physiotherapists-world-allowed-prescribemedicines-patients.html>. Accessed 9 March 2013.

[2] Department of Health, Social Services and Public Safety (2004). Best Practice Guidance for Supplementary Prescribing by Nurses within the HPSS in Northern Ireland. www.department-of-HealthSocialServices-andPublic.Safety.com. Accessed 19 March 2014

[3] Physiotherapy Pain Association (2007). Supplementary Prescribing- can it have a place in pain management physiotherapy? A personal review.

[4] Courtenay M and Griffiths M (2010). Independent and Supplementary Prescribing: An Essential Guide. Cambridge: Cambridge University Press ; 2010.

[5] Chartered Society of Physiotherapy (2004). Prescribing Rights for Physiotherapists - an update August 2004 page 11. www.csp.prescribingrights forphysiotherapists.com. Accessed $13^{\text {th }}$ August 2013.

[6] Chatered society of physiotherapy (2012). UK physiotherapists first in the world to prescribe medicines independently after campaigning by CSP. pressoffice@csp.org.uk.

[7] Onigbinde Ayodele Teslim, Bamitale Kayode D S, Olaogun Matthew O B, Makinde Olufisayo Olukemi, Adetoogun Gbadegesin Elubode, Odeyemi Emmanuel (2012). Opinion and knowledge of Nigerian physiotherapists on relevance and usefulness of pharmacology education on dosage of topical medications. International journal of pharmacy and pharmacology, vol 2 (4), 55 - 63

[8] Onigbinde Ayodele Teslim, Adereni Adebiyi Solomon, Bamitale Kayode D S, Kambalametore SVK, M'kumbuzi Vyvienne, Margaret Wazakili (2013). Changing the prescription status of physiotherapists: Perception of Nigerian physiotherapists. Vol. 16, No 2 (2013), Available at http://www.njmr.org.ng. Accessed on $17^{\text {th }}$ June 2014.

[9] MHRA (2013). Supplementary Prescribing.Available at: $<$ http://www.mhra. gov.uk/ How we regulate/ Medicines/ [Accessed 9 March, 2013].

[10] Emmerton L, Marriott J, Bessell T, Nissen L, Dean L (2005). Pharmacists and Prescribing Rights: Review of International Developments. J Pharm Pharmaceut Sci; 8(2):217-225.

[11] LeCraw L. L (2007). Use of clinical practice guidelines in medical malpractice litigation. American society of Clinical Oncology, Me Rev Stat Ann Tit 24, 2971 - 2979.

[12] Onigbinde Ayodele Teslim, Oyeniran Tolulope Olaoluwa, M'Kumbuzi Vyvienne, Mlenzana Nondwe, Manie Shamilar, Tarimo Nesto, Mukoka Grace (2014). Physiotherapists as Supplementary Prescribers: Opinion of Nigerian doctors. Submitted for publication in the American journ of Health Research.

[13] Australian Medical Association (2012). AMA takes strong stance on non-medical prescribing. Available through: https://ama.com.au/media/ama-takes-strong-stance-nonmedical prescribing Accessed 29 August, 2013.

[14] Moore RA, Tramer MR, Carroll D, Wiffen PJ, McQuay HJ (1998). Quantitative systematic review of topically applied non-steroidal anti-inflammatory drugs. Brit. Med. J; 316: 333338.

[15] Grimmer K, Kumar S, Gilbert A and Milanese S (2002). NonSteroidal Anti-Inflammatory Drugs (NSAIDs): Physiotherapists' use, knowledge, and attitudes. Australian Journal of Physiotherapy; 48, pp. 82-91.

[16] Active care physiotherapy clinic (2014). Muscle relaxant. www.activecare physiotherapyclinic/musclerelaxant. Accessed on $28^{\text {th }}$ June 2014.

[17] Ger L.P, Lee M.C, Wong C.S, Chao S.S, Wang J. J, Ho S.T (2003). The effects of education and clinical practice on knowledge enlightenment; and attitude towards the use of analgesic for cancer pain among physicians and medical students. Acta anaethesiol. Sin, 41 (3); $105-114$.

[18] Department of Health (2005). Supplementary prescribing by Nurses, Pharmacists, Chiropodists/Podiatrists, Physiotherapists and Radiographers within the NHS in England. A guide for implementation. Accessed on the $17^{\text {th }}$ March 2014.

[19] Chartered Society of Physiotherapy (2013). Practice guidance for physiotherapist supplementary and/or independent prescribers in the safe use of medicines. (2nd Edition). [Accessed 29 August, 2013]. 